\title{
DROPLET DISTRIBUTION AND CONTROL AGAINST CITRUS LEAFMINER WITH UAV SPRAYING
}

\author{
Zhang Pan,* Wang Kejian,, Lyu Qiang, ${ }^{*}$ He Shaolan, ${ }^{*}$ Yi Shilai, ${ }^{*}$ Xie Rangjin, ${ }^{*}$ Zheng Yongqiang, \\ Ma Yanyan,* and Deng Lie*
}

\begin{abstract}
To explore the applicability of unmanned aerial vehicle (UAV) in the citrus orchard, this study was initiated to evaluate the droplet distribution by the UAV spraying, the difference of control effect against the citrus leafminer (Phyllocnistis citrella Stainton) (CLM) and the economic benefits between UAV spraying and manual spraying under the condition of different citrus tree shapes. These experiments were conducted at the sprouting-growing period of citrus autumn shoots with five-year-old Tarocco blood orange. The results presented that hedgerow-shaped plants have the best performance of droplet distribution and shoots' protective effect (SPE) under the conditions of UAV spraying. The CLM leaf damage index (LDI) by manual spraying was lower than that by the UAV spraying, especially for open centre shape. Overall, the CLM control effect by the UAV spraying is about $65-75 \%$ of that by the manual spraying. These results indicated that the droplet distribution and the CLM control effect of the hedgerow-shaped and the open-centreshaped canopy by the UAV spraying achieved a better performance than that of the round-head-shaped plants. The results of droplet distribution and CLM control effect demonstrated that open-centreshaped canopy has relatively satisfactory performance. Compared with the manual spraying, UAV spraying got high efficiency and low cost performance.
\end{abstract}

\section{Key Words}

UAV spraying, droplet distribution, citrus leafminer, control effect, economic benefits

\section{Introduction}

Citrus is one of the foremost and profitable fruit crops but unfortunately its present status is threatened by a number of problems including low production induced by pests. Of all the agricultural pests and diseases that threaten citrus crop, citrus leafminer (CLM; Phyllocnistis ciirella

\footnotetext{
* Citrus Research Institute, Southwest University, People's Republic of China; e-mail: zhangpan@sinocitrus.com, wangkejian12@163.com, \{lvqiang, heshaolan, yishilai, xierangjin, zhengyongqiang, mayanyan, denglie\}@cric.cn

Recommended by Prof. Howard Li
}

(DOI: 10.2316/Journal.206.2017.3.206-4980)
Stainton) is considered to be a major destructive pest [1], [2], which can cause a huge loss of citrus fruit quality. CLM occurs from summer to autumn and it mainly damage the autumn shoot [3], [4]. The CLM larvae caused damage by eating the mesophyll tissue or parenchymatic tissue and making many zigzag silvery mines [5], [6] in the upper and lower epidermal layers of young leaves and shoots. As a consequence, the leaves attacked by CLM were twisted or folded over and the damage gradually spread to the whole leaf tissue. Citrus leaf miner was also active throughout the year and multiplied on young growth of citrus plants. CLM damaged above $20 \%$ of the annual new leaf area of mature trees and yield was usually affected by reducing the shoots growth [6]-[8], photosynthetic area [1], [6] and the quality of flowers and fruits in the plant. Wounding caused by CLM accelerates the spread of citrus canker disease [1], [9]-[11] by the direct penetration of the bacterium. The twisted leaves also provide wintering sites for red mite, moth and other pests. Therefore, the CLM is one of the most important destroyers of citrus production and fruit quality.

At present, the CLM control relies primarily on chemical pesticide in China. CLM occurs many generations every year even with overlapped generations, which could increase the difficulty in prevention and management of CLM. Most of our orchards still adopted backward spraying machinery with low utilization efficiency and operating efficiency [12] for insect disease prevention, such as knapsack sprayer, pedal sprayer and high-pressure sprayer [13], [14]. Consequently, farmers had to widely apply pesticides to improve the control effect. This will bring about serious pesticides waste, environmental pollution, pesticide residues in citrus fruits, and even lead to the pesticide poisoning during the workers closely stay with pesticide environment in the orchard canopy [15], [16]. It follows that CLM control is one of the most important and high-cost compounds in the process of citrus cultivation management.

Accelerating the plant protection mechanization and improving the ability of citrus diseases and pests control are inevitable requirement of the stable high yield, good fruit quality and safety, farmer's life safety and protection of agricultural ecological environment. Many researchers 
devote themselves to researches and technologies on plant protection machinery and agricultural aviation which laid a solid foundation for agricultural aviation applications. Especially about the rotor unmanned aerial vehicle (UAV) with many advantages, such as its small size, high flexibility, no requirement for takeoff site and driver, frequent takeoffs and landings under high temperatures [17]-[20]. In addition, it has shown a good adaptability during hilly terrains and closed orchard even increases the droplet penetration by severe turbulence of the rotor.

UAV spraying and other related technology were gradually strengthened through many researchers from China and other countries [21]-[26], and it provides us the good application prospect against CLM and increases orchard productivity. The CLM control effect using JT10 UAV in citrus orchard was studied for the first time to establish effective and safety aerial spraying technology. These results will provide the basis for the further optimization of the small UAV spraying technology.

\section{Materials and Methods}

\subsection{Materials}

\subsubsection{Test Condition}

The experiments were conducted from mid-August to the end of September 2015 in Citrus Research Institute, Chinese Academy of Agricultural Sciences, Chongqing,

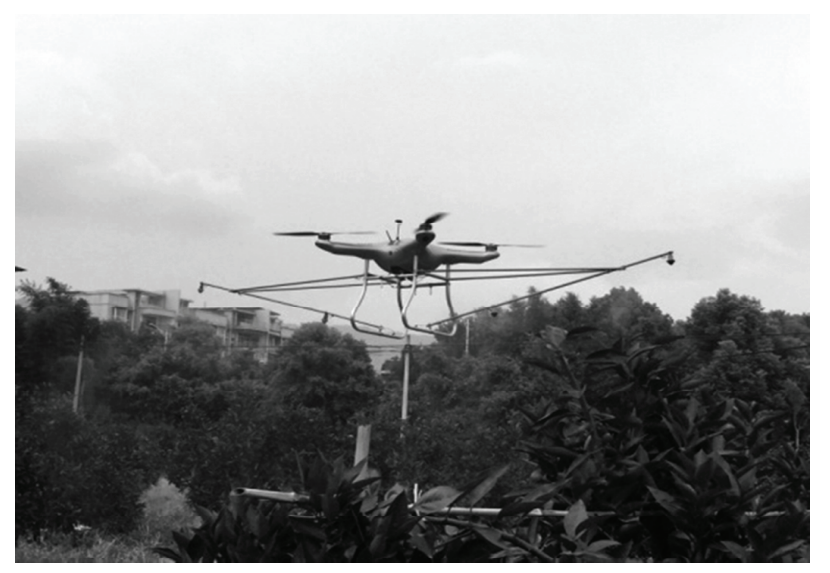

Figure 1. The UAV used in the experiments.
China $\left(29.81^{\circ} \mathrm{N}, 106.40^{\circ} \mathrm{E}\right)$. The five years Tarocco blood orange (Citrus sinensis cv. Tarocco) grafted on Carrizo Citrange (Citrus sinensis $\times$ Poncirus trifoliate, "Carrizo Citrange") were chosen as the test material.

In the experiments, 1.8\% Avermectin (Zhejiang Hisun Chemical Co., Ltd, Taizhou City, China) were used as pesticide against CLM under field conditions, and the ponceau 2R (Shanghai Jinsui Bio-Tech Co., Ltd, Shanghai City, China) were used as the droplet indicator.

\subsubsection{Test Device}

Aircraft spray system is JT10 UAV (Chongqing Kingtec Aviation Industry Co., Ltd, Chongqing City, China) with the $10-\mathrm{L}$ container capacity, pressure nozzle, $4.0-6.0 \mathrm{~m}$ spray swath, relative flight height to canopy $0.5-4.0 \mathrm{~m}$, operation speed $0-10.0 \mathrm{~m} / \mathrm{s}$ and $80-120 \mu \mathrm{m}$ droplet size. UAV fly at a speed of $1 \mathrm{~m} / \mathrm{s}$ over the top $1 \mathrm{~m}$ above the canopy (Fig. 1). And the other spraying equipment used as the control in the experiment was the WS-18D knapsacktype electric sprayer (Shandong Wish Plant Protection Machinery Co., Ltd, Linyi City, China) with $6.4 \mathrm{~kg}$ net weight, $380 \times 260 \times 570 \mathrm{~mm}$ size, $20 \mathrm{~L}$ container capacity and 0.15-0.4 MPa pressure.

\subsection{Method}

\subsubsection{The Droplet Distribution Test}

The sampling sites and different citrus tree shapes are presented in Fig. 2. The top, middle (2/3 plant height) and lower ( $1 / 3$ plant height) parts of citrus trees crown were flagged by hanging six white pulp paper cards of the plants. With the citrus trunk for the central line, the front, middle and the rear direction of the left side and the right side were laid out three paper cards in sequence.

Each sampling paper card was $76 \mathrm{~mm} \times 50 \mathrm{~mm}$ size which was nearly the same size as a citrus leaf. The spray solution was 300 times Ponceau 2R (99.5\% purity). Dried paper cards were collected one by one in zip lock bags after spraying. Then, the parameters including the droplet coverage rate, droplet deposition density, droplet size and droplet deposition uniformity were analysed. Droplet coverage rate means the percentage of the chemical reagent area covered on the paper card. Droplet deposition density means the number of droplets per unit area on the paper card.

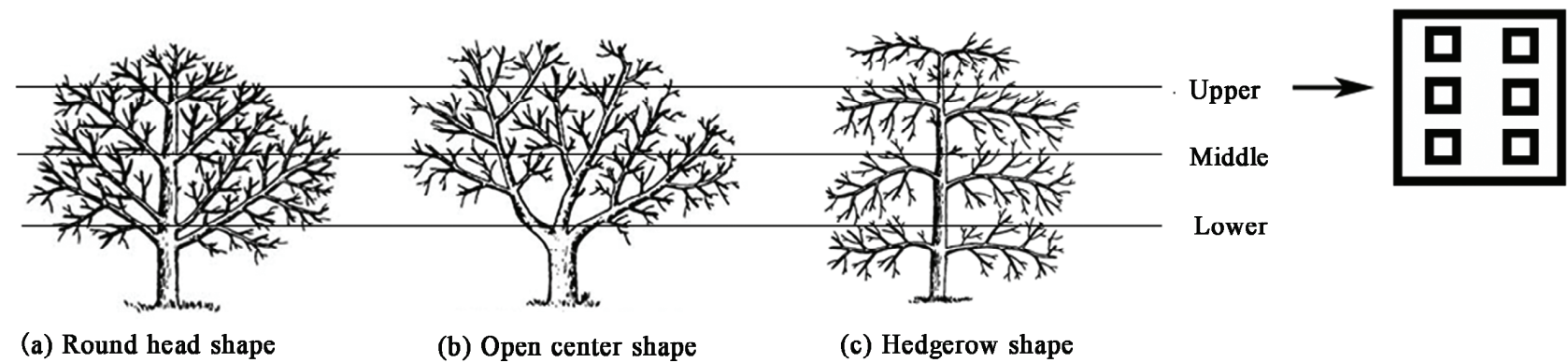

Figure 2. The sampling schemes of different citrus tree shapes. 


\subsubsection{CLM Control Effect Experiment}

The new buds and flushes were removed five times with interval three days from July to mid-August for making the autumn shoots neatly grow. The chemicals were sprayed every 5 days for three times under the condition that the autumn shoots sprout rate were above $30 \%$ at about 4 days after the last time of new buds were removed. And the chemical solution was diluted 1000 times of $1.8 \%$ Abamectin. No spraying treatment as blank control which means only water spraying.

\subsection{Data Analysis}

EXCEL software was used for data analysis. SPSS17.0 software was used for the variance and correlation analysis.

\subsubsection{The Parameters of Droplet Deposition Distribu- tion}

The parameters of droplet deposition distribution, such as droplet coverage, droplet deposition density and droplet size, were analysed by the image processing software named Image J.

\subsubsection{The Control Effect of CLM}

The total number of young shoots was manually counted the vulnerability of CLM at the time of autumn shoots matured, September 16 after chemicals spraying.

The disease grades for CLM are shown in Fig. 3 where Grade 0 indicates that leaves were not injured; Grade 1 indicates that leaf had silvery mines but without twisted; Grade 3 indicates that leaf had silvery mines and also twisted; Grade 5 indicates that leaf with half twist; Grade 7 indicates leaf with full twist and defoliation.

The equations for calculating leaf damage index (LDI) and shoots' protective effect (SPE) [27] are given as follows:

\section{LDI \\ $=\frac{\sum(\text { different grades } * \text { the number of leaves in different grade })}{\text { the highest grade } * \text { total leaves }} * 100$}

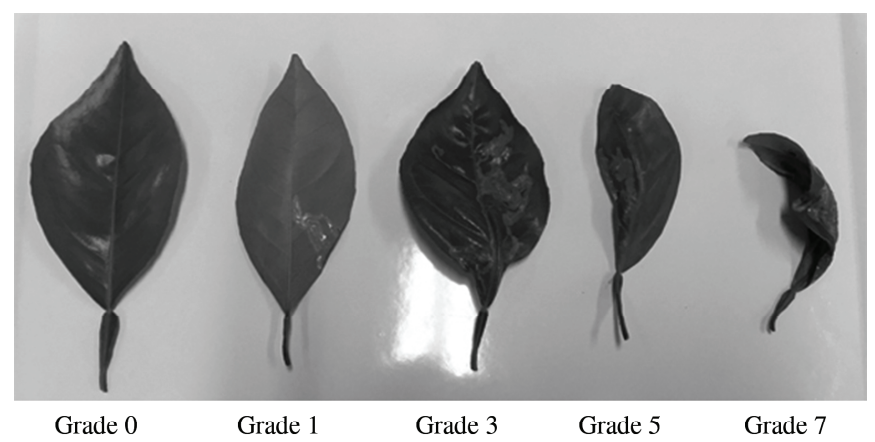

Figure 3. The damage grades of citrus leafminer.
$\operatorname{SPE}(\%)$

$=\frac{\text { LDI without spraying }- \text { LDI with spraying treatment }}{\text { LDI without spraying }} * 100$

which indicates the percentage changes caused by spraying over no spraying.

\subsubsection{The Direct Influence on Citrus Crops}

No obvious pesticide pollution and normal growing of citrus trees was found in the treatment area and control area.

\subsubsection{The Influence on Other Creatures}

The other diseases and insect pests lightly impacted on this chemical pesticide in late July with the high temperature. All of the test area and the surroundings were citrus crops, no wildlife, fish, less natural enemy insects in the field, and the influence of pesticides on non-target creatures is not obvious.

\section{Results and Analysis}

\subsection{Effect of Different Tree Shapes on Droplet Distribution}

The significant negative correlations were found between the leaf area index and droplet deposition density [28]. Therefore, proper pruning of the citrus canopy will help to reduce the canopy leaf area index and effectively improve the droplet distribution of UAV spraying. Figure 4 shows the comparative analysis results of droplets distribution on the round head shape, open-centre-shaped and hedgerow-shaped crown by the UAV spraying. It not only reflects the droplet distribution along the height direction of the citrus plants, but also reflects the influence of different citrus tree shapes on the droplet deposition. The open-centre-shaped canopy and hedgerow-shaped crown, to some extent, can improve the droplet distribution in each layer of the citrus crown. Moreover, the droplet distribution of the hedgerow-shaped citrus canopy reached record levels. The droplet particle sizes at the three different tree-shape canopies had no significant difference.

From the specific perspectives, the round-head-shaped canopy got minimum droplet coverage rate, droplet deposition density and the number of droplets which was $8.25 \%$, 48.70 droplets per square centimeter and 1,816, respectively. Its natural structure always brings about some phenomena, such as high canopy density and intersection with wide spreading branches and luxuriant foliage, resulting in the unsatisfied droplets deposition effect, fruit branch shifting outwards and inside bareness of tree, and poor fruit yield and quality [29]. The general trend of droplet distribution decreased with the citrus canopy height. During the UAV spraying process, the upper citrus canopy which has the nearest distance between upper canopy and UAV obtained more droplets. It can be seen that most droplets on the surface canopy had weak penetration and 


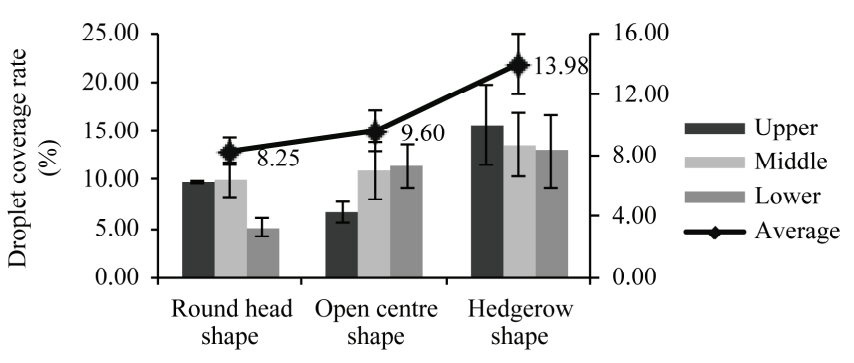

(a)

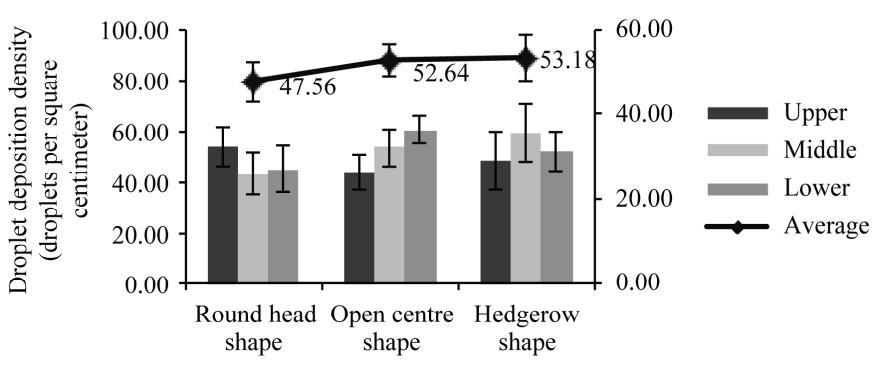

(b)

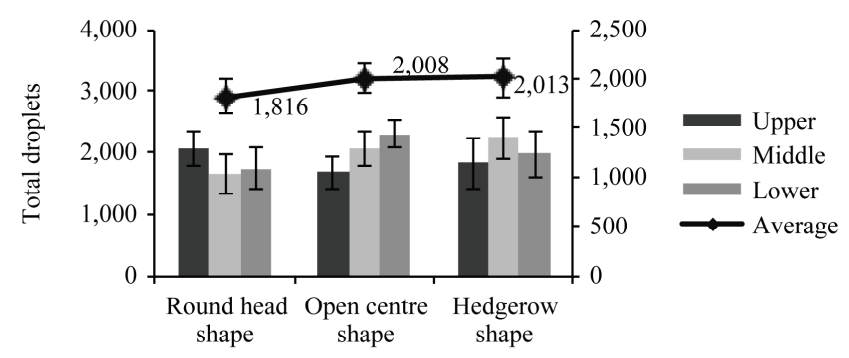

(c)

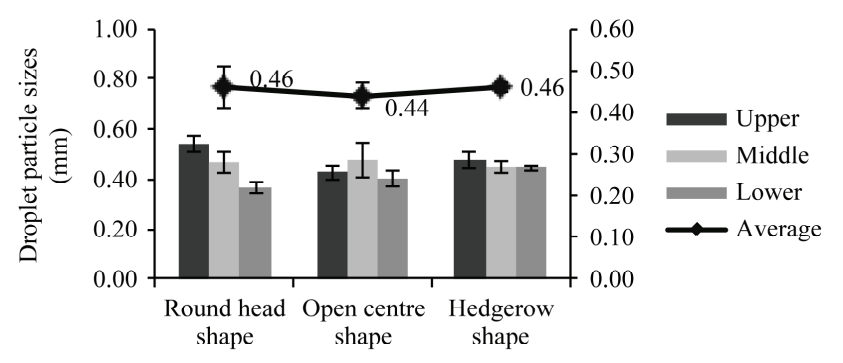

(d)

Figure 4. The droplet distribution coverage of different citrus tree shapes by the UAV spraying: (a) droplet coverage rate; (b) droplet deposition density; (c) total droplets; and (d) droplet size.

poor deposition effects due to interaction of citrus leaves and branches. 10, 0000 branches per 667 square meters are optimal for citrus cultivation and management [22]. More branches decreased the fruit yield and increased the occurrence of pests, and these pests incline to stay inner humid canopy than in the dangerous outer canopy which could easily be captured by some natural enemy. Deep and uniform droplet distribution is the basic requirements of orchard spraying operation. It was apparent that the round-head-shaped citrus canopy was not suitable for UAV spraying operation in citrus orchard.

In these circumstances, we changed the citrus tree shape from the round head type to the open centre type and hedgerow-shaped canopy. These agronomic measures were carried out to increase the droplet deposition density. The open-centre-shaped canopy greatly raised the level of droplet distribution. The droplet coverage rate, the droplet deposition density and the number of droplets were increased by $16.36 \%, 10.68 \%$ and $10.57 \%$ compared with the round-head-shaped citrus canopy, respectively. The morphology structure characteristics of open-centreshaped crown are without the central trunk and open centre shape with sparse leaves in middle canopy and light ventilation. Based on these factors, most of the droplets were widely distributed in the middle and lower canopies, less in the upper canopy. The open centre crown had better droplet deposition effect, usually applied in the process of citrus orchards management. Total branches and light ventilation of the citrus canopy were subject to citrus canopy shape; hence, reasonable citrus tree shape was the basis for fruit quality and high yield. The combination of droplet deposition and actual situation of citrus orchard application indicated that open centre crown was suitable for UAV spraying in citrus orchards. However, the thin canopy with low leaf density cannot resist the strong airflow of the UAV induced many droplets distributed on the middle and lower leaves.

The citrus orchard has remained predominantly in round head type and open centre type [22], very little in hedgerow-shaped citrus orchard. However, other fruit crop research on hedgerow-shaped canopy [30]-[32] is really more than citrus on it. From Fig. 4, we can see that hedgerow-shaped crown had the best performance of droplet deposition with its higher droplet coverage $(13.98 \%)$, droplet deposition density and droplet deposition quantity. There was no obvious difference among the droplet deposition density, droplet deposition quantity and droplet particle size of hedgerow-shaped crown and open-centre-shaped canopy. The droplet coverage rate, the droplet deposition density and the number of droplets on the hedgerow-shaped canopy increased by $69.45 \%, 11.82 \%$ and $10.85 \%$ compared with the round-head-shaped citrus canopy, respectively. These data with big discrete degree had no significant difference among the upper, middle and lower layers along the citrus height direction. The hedgerow-shaped citrus canopy with simple structure is convenient for mechanization. But the contradiction between the droplet distribution and the economic benefit should be solved by further improvement of spraying machine and citrus tree shape transformation. There are also inevitable accidental errors occurring in the pruning process, and the different pruning levels contribute to the large discrete degree of droplet deposition density and non-uniform distribution.

\subsection{Effect of Aerial Spraying on CLM Control}

The different citrus tree shapes were closely related to the droplet distribution, further affecting the CLM control. The results shown in Table 1 not only estimated the effect of different citrus tree shape on the CLM control effect, but also evaluated the good and bad points of UAV spraying and manual spraying. The results of statistical 
Table 1

Effect Comparison by Different Spray Methods and with Different

Citrus Tree Shapes Against Citrus Leaf Miner

\begin{tabular}{|l|l|c|c|c|}
\hline Tree Shapes & Treatment & LDI & CV (\%) & SPE (\%) \\
\hline \multirow{5}{*}{ Round head shape } & UAV spraying & $6.32 \pm 0.52 \mathrm{~b}$ & 16.46 & 29.90 \\
\cline { 2 - 5 } & Manual spraying & $5.28 \pm 0.28 \mathrm{~b}$ & 9.09 & 41.43 \\
\cline { 2 - 5 } & Without spraying & $11.92 \pm 1.30 \mathrm{~d}$ & 15.44 & - \\
\hline \multirow{3}{*}{ Open centre shape } & UAV spraying & $5.99 \pm 0.76 \mathrm{~b}$ & 25.21 & 31.76 \\
\cline { 2 - 6 } & Manual spraying & $3.51 \pm 0.34 \mathrm{a}$ & 16.52 & 60.02 \\
\cline { 2 - 6 } & Without spraying & $8.78 \pm 0.00 \mathrm{c}$ & 0 & - \\
\hline \multirow{3}{*}{ Hedgerow shape } & UAV spraying & $5.41 \pm 0.77 \mathrm{~b}$ & 28.65 & 38.52 \\
\cline { 2 - 6 } & Manual spraying & $3.87 \pm 0.23 \mathrm{a}$ & 10.34 & 56.06 \\
\cline { 2 - 6 } & Without spraying & $8.11 \pm 0.65 \mathrm{c}$ & 11.22 & - \\
\hline
\end{tabular}

Notes: The data in the table are mean \pm SD. Data followed by different small letters are significantly different among different treatments at the $\alpha<.05$ level by Duncan's new multiple range test.

analysis indicate that the LDI of spraying treatment and CK had a significant difference on different citrus tree shape, and the round head shape obtained the highest LDI, 11.92. Perhaps it is relevant to the essential features of the round-head-shaped citrus with wide-spreading branches and luxuriant foliage. New shoots spring up after erasing the new buds has provided the comfort environment for CLM. The simple structure of open-centre-shaped and hedgerow-shaped citrus canopy induced less new shoots and lower LDI compared with round head crown, and there was no significant difference of LDI between them.

The manual spraying had the lowest LDI among all treatments, the LDI of UAV spraying and manual spraying showed a statistically significant difference not just for open-centre-shaped but for hedgerow-shaped citrus canopy. The LDI of manual spraying decreased by $16.46 \%, 41.40 \%$ and $28.47 \%$, respectively, in comparison with the UAV spraying under the circumstances of round head shape, open-centre-shaped and hedgerow-shaped citrus canopy. And the CV of LDI by the manual spraying is relatively low $9.09 \%, 16.52 \%$ and $10.34 \%$, respectively; it means that the data are uniform and smaller discrete degree. There are signs that the SPE against CLM, with hedgerow shape the best, open centre shape the second, round head shape the worst. Overall, the SPE of UAV spraying had a poor effect from $30 \%$ to $40 \%$ compared with manual spraying from $40 \%$ to $60 \%$. Manual spraying could receive satisfactory performance - uniform coverage, good SPE and low LDI, whereas the UAV spraying had the weak effect attributed to the tree shape, the canopy structure, nozzle type, the environment conditions and so on.

The comparison of CLM control effect on different plant canopy shapes and different spraying methods is shown in Fig. 5. It is clear that hedgerow-shaped citrus canopy had the highest healthy leaf ratio varied widely among spraying treatment, ranging from $91.51 \%$ by UAV,
$91.39 \%$ by manual and $81.54 \%$ by control. It means that UAV spraying to the hedgerow-shaped canopy showed a relatively satisfactory control effect to CLM because of its least severely injured leaves in all of the treatment and similar healthy leaves ratio to the control. The damaged leaf ratio of CLM mostly at Grade 1, Grade 3 and Grade 5, and Grade 3 accounted for the highest proportion; Grade 7 had the least rate.

\subsection{Cost and Benefit Analysis of the UAV Spraying}

The comparison of the economic benefits between UAV spraying and manual spraying is shown in Table 2. The price of a multi-rotor spraying UAV ranged from 50,000 to 300,000 RMB and the knapsack electric sprayer price only from 200 to 300 RMB. The rotor UAV sprayer is expensive to the general users and has higher equipment cost than knapsack electric sprayer.

A fair proportion of farmers were attracted by the efficient agricultural UAV with the rapid development of plant protection machinery. Companies across the China are beginning to offer the rental service to meet the demand of small disperse land, the prices ranged from 150 to 300 RMB per hectare. Compared with the field operation cost, the manual spraying operation ranged from 1500 to $3000 \mathrm{RMB}$ per hectare. The cost of aerial spraying is significantly lower than that of the manual spraying operation. That means that UAV spraying services not only have the price advantage, but also have the high efficiency superiority. The field test condition displayed that the $2-3$ operators work together could spray about 20-35 hectares per day. The field work efficiency of the UAV spraying is nearly 30 times higher than that of the manual spraying with $0.67-1.34$ hectares for each person a day. Meanwhile, the pesticide consumption of the UAV spraying operation is only $1 / 2$ of the manual spraying, 


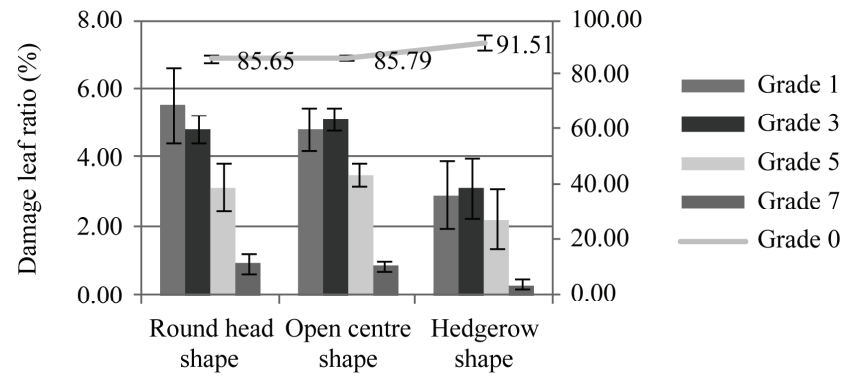

(a)

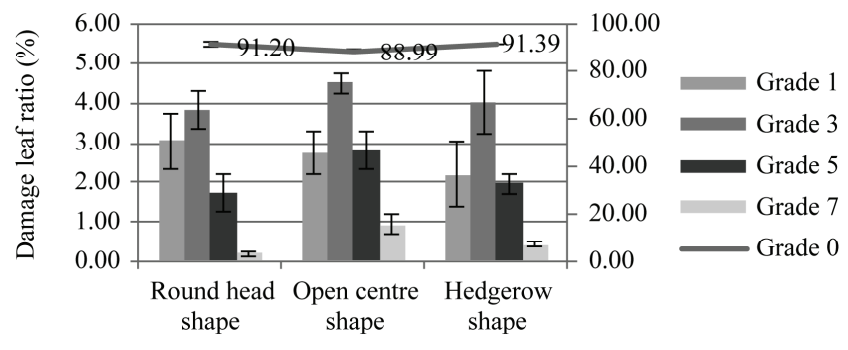

(b)

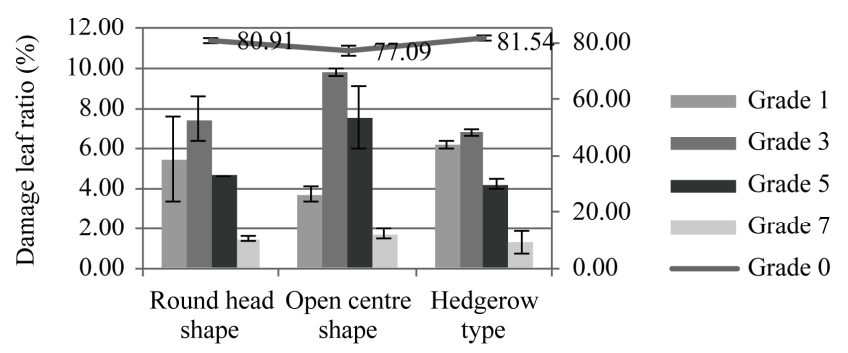

(c)

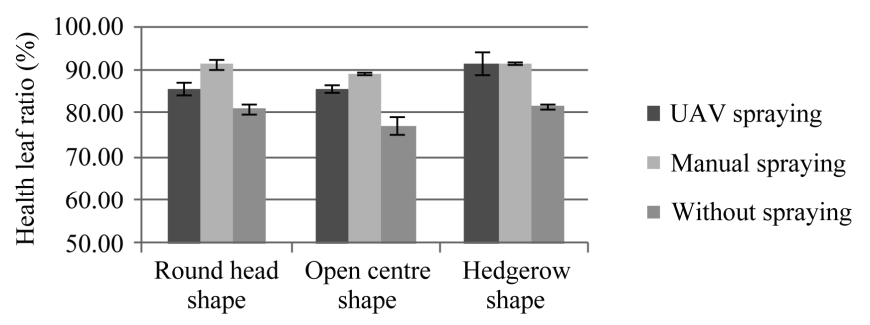

(d)

Figure 5. The comparison of leaf ratios with different citrus tree shapes and different spraying methods: (a) the damage leaf ratio with UAV spraying; (b) the damage leaf ratio with manual spraying; (c) the damage leaf ratio without spraying; and (d) the health leaf ratio with different spraying machines.

it greatly reduces the pesticide waste and orchard management cost. Combined with the SPE data of UAV spraying and manual spraying, it can be seen that the UAV control effect against CLM in the field is about $65-75 \%$ for manual spraying, it also needs to be improved. The use of UAV in citrus orchard still exist many obstacles impaired control effect against citrus disease and insect pest. About the UAV technical side, combining the electrostatic nozzle [33], [34] and aerial adjuvant [35], [36] in the field test with the optimal spraying pressure [37], [38] can improve the droplet deposition. In addition, the field test should pay attention to the proper weather condition, especially regarding wind speed. About the citrus cultivation techniques, exploring the recovery period of hedgerow-shaped canopy was critical for citrus yield and quality. The comparison of annual output and income on open-centre-shaped and hedgerowshaped citrus orchard to explain which kind of citrus tree shape was suitable for the use of UAV in citrus orchard.

\section{Conclusion}

In this paper, by comparing the UAV spraying and manual spraying on the condition of different citrus tree shapes, the UAV applicability to the citrus orchard was explored in terms of droplet distribution, control effect against the CLM and the economic benefits. The concluding remarks are as follows.

1. The droplet distribution of citrus middle layer was largely increased by citrus tree-shaped transformation. The hedgerow-shaped crown obtained the best droplet deposition performance by the UAV spraying. There was no obvious difference among these droplet deposition parameters of hedgerow-shaped crown and opencentre-shaped canopy.

2 . The manual spraying showed satisfactory performance on the CLM control effect with all citrus tree shapes. The hedgerow-shaped and the open-centre-shaped citrus canopy had relatively a better control effect against CLM by the UAV spraying. Besides, previous experiences demonstrated that open-centre-shaped canopy is a proper canopy structure to maintain the citrus fruit yield. The practical application of hedgerow-shaped orchards also needs further research.

3. The UAV spraying achieved high efficiency and lowcost performance, while the CLM control effect of it merely about $65-75 \%$ of manual spraying. Therefore, the UAV field application could be improved by the combination of related technology and field circumstance.

Table 2

Comparison of the Economic Benefits with UAV Spraying and Manual Spraying

\begin{tabular}{|l|c|c|c|c|c|}
\hline & $\begin{array}{c}\text { Sprayer Price } \\
(\mathrm{RMB})\end{array}$ & $\begin{array}{c}\text { Labour Cost (RMB) } \\
(\mathrm{RMB})\end{array}$ & $\begin{array}{c}\text { Efficiency } \\
\text { (hectares/day) }\end{array}$ & $\begin{array}{c}\text { Pesticide Cost } \\
(\mathrm{RMB})\end{array}$ & SPE (\%) \\
\hline UAV spraying & $50,000-300,000$ & $150-300$ & $20-35$ & $25-40$ & $30-40$ \\
\hline Manual spraying & $200-300$ & $80-180$ & $0.67-1.34$ & $50-75$ & $40-60$ \\
\hline
\end{tabular}

Note: The data of the equipment cost, labour cost and pesticide cost were at per hectare. 


\section{Acknowledgement}

The authors would like to acknowledge financial support from China National key research and development project (2016YFD0200703), Fundamental Research Funds for the Central Universities (XDJK2016D050), China National Science \& Technology Support Program (2014BAD16B0103), Jiangxi Province 2011 Collaborative Innovation Special Funds "Co-Innovation Center of the South China Mountain Orchard Intelligent Management Technology and Equipment" (Jiangxi Finance Refers to [2014] NO 156).

\section{References}

[1] M. Atiq, M.A. Khan, S.T. Sahi, and R. Ahmad, Genetic response of citrus germplasm against citrus leafminer, Journal of Animal and Plant Sciences, 23(1), 2013, 240-243.

[2] M.M. Mckenna, E.M.A.F. Hammad, and M.T. Farran, Effect of Melia azedarach (Sapindales: Meliaceae) fruit extracts on citrus leafminer Phyllocnistis citrella (Lepidoptera: Gracillariidae), SpringerPlus, 2(1) 2013, 144.

[3] J. Belasque Jr., A.L. Parra-Pedrazzoli, N.J. Rodrigues, et al., Adult citrus leafminers (Phyllocnistis citrella) are not efficient vectors for Xanthomonas axonopodis pv. Citri, Plant Disease, $89(6), 2005,590-594$.

[4] G.P. Bernet, C. Margaix, J. Jacas, E.A. Carbonell, and M.J. Asins, Genetic analysis of citrus leafminer susceptibility, Theoretical and Applied Genetics, 110(8), 2005, 1393-1400.

[5] J.C. Legaspi, J.V. French, A.G. Zuniga, and B.C. Legaspi, Population dynamics of the citrus leafminer, Phyllocnistis citrella (Lepidoptera: Gracillariidae), and its natural enemies in Texas and Mexico, Biological Control, 21(1), 2001, 84-90.

[6] A. Raga, M.E. Satol, M.F. Souza, and R.C. Siloto, Comparison of spray insecticides against citrus leafminer, Arquivos Do Instituto Biologico (Sao Paulo), 68, 2001, 77-82.

[7] X.N. Zeng, M.L. Wu, S. Luo, and S.H. Zhao, Role of three botanical insecticides on the control of citrus leafminer (Phyllocnistis citrella Stainton), Acta Universitatis Agriculturalis Boreali-occidentalis, 29(6), 2000, 54-56.

[8] M.E. Rogers and P.A. Stansly, Florida citrus pest management guidelines: Asian citrus psyllid and citrus leafminer, Florida Cooperative Extension Service, Institute of Food and Agricultural Sciences, University of Florida, ENY-734, 2007.

[9] M. Mustafa, M. Imran, A. Rasool, M. Azeem, A. Riaz, and M. Afzal, Evaluation of commercial citrus cultivars for resistance to citrus leaf miner and its management, Journal of Entomology and Zoology Studies, 2(6), 2014, 213-216.

[10] R.S.C. Christiano, M. Dalla Pria, W.C. Jesus Junior, J.R.P. Parra, L. Amorim, and A. Bergamin Filho, Effect of the citrus leaf-miner damage, mechanical damage and inoculum concentration on severity of symptoms of Asiatic citrus canker in Tahiti lime, Crop Protection, 26(2), 2007, 59-65.

[11] W.C. Jesus Jr., J. Belasque Jr., L. Amorim, R.S.C. Christiano, J.R.P. Parra, and A. Bergamin Filho, Injuries caused by citrus leaf miner (Phyllocnistis citrella) exacerbate citrus canker (Xanthomonas axonopodis pv. citri) infection, Fitopatologia Brasileira, 31(3), 2006, 277-283.

[12] H.F. Zang and L.Y. Xu, Summary of research status on orchard sprayer, Journal of Chinese Agricultural Mechanization, 35(3), 2014, 112-118.

[13] W. Qiu, W.M. Ding, X.M. Fu, X.C. Wang, X.L. Lyu, and Y.N. Li, Design and experiment of ring double-channel fan for spraying machine in orchard, Transactions of the Chinese Society Agricultural Engineering, 28(12), 2012, 13-17.

[14] X.K. He, Improving severe draggling actuality of plant protection machinery and its application techniques, Transactions of the Chinese Society Agricultural Engineering, 20(1), 2004, $13-15$.

[15] X.M. Fu, X.L. Lyu, W.M. Ding, P. Wu, S.M. Ding, and W. Qiu, Present state and technical requirement about plant protection machinery in China, Chinese Agricultural Mechanization, (6), 2009, 10-13, 17.

[16] S.R. Song, T.S. Hong, D.Z. Sun, Y.Q. Zhu, and X.D. Peng, Droplet deposition in variable-speed spraying experiment of air blast sprayer, Journal of Agricultural Mechanization Research, 31(1), 2009, 166-169.

[17] Z.Y. Zhou, Y. Zang, X.W. Luo, Y.B. Lan, and X.Y. Xue, Technology innovation development strategy on agricultural aviation industry for plant protection in China, Transactions of the Chinese Society of Agricultural Engineering (Transactions of the CSAE), 29(24), 2013, 1-10.

[18] Y. Huang, W.C. Hoffmann, Y.B. Lan, W. Wu, and B.K. Fritz, Development of a spray system an unmanned aerial vehicle platform, Applied Engineering Agriculture, 25(6), 2009, 803-809.

[19] X.Y. Xue, K. Tu, W.C. Qin, Y.B. Lan, and H.H. Zhang, Drift and deposition of ultra-low altitude and low volume application in paddy field, International Journal of Agricultural and Biological Engineering, 7(4), 2014, 23-28.

[20] Y.B. Huang, S.J. Thomson, W.C. Hoffmann, Y.B. Lan, and B.K. Fritz, Development and prospect of unmanned aerial vehicle technologies for agricultural production management, International Journal of Agricultural and Biological Engineering, 6(3), 2013, 1-10.

[21] H.J. Asl, G. Oriolo, and H. Bolandi, An adaptive scheme for image-based visual servoing of an underactuated UAV, International Journal of Robotics and Automation, 29(1), 2014, 92-104.

[22] C. Kownacki, Successful application of miniature laser rangefinders in obstacle avoidance method for fixed wing MAV, International Journal of Robotics and Automation, 28(3), 2013, 292-298.

[23] T. Chettibi, Generating near-optimal reference trajectories for small fixed-wing UAVs, International Journal of Robotics and Automation, 26(2), 2011, 187.

[24] B.S. Faiçal, F.G. Costa, G. Pessin, et al., The use of unmanned aerial vehicles and wireless sensor networks for spraying pesticides, Journal of Systems Architecture, 60(4), 2014, 393-404.

[25] Y. Huang, W.C. Hoffman, Y.B. Lan, B.K. Fritz, and S.J. Thomson, Development of a low-volume sprayer for an unmanned helicopter, Journal of Agricultural Science, 7(1), 2014, 148-153.

[26] D.Y. Zhang, L.P. Chen, R.R. Zhang, et al., Evaluating effective swath width and droplet distribution of aerial spraying systems on M-18B and Thrush 510G airplanes, International Journal of Agricultural and Biological Engineering, 8(2), 2015, 21-30.

[27] H. Jiang, GB/T 17980.58-2004, Pesticide-Guidelines for the field efficacy trials (II)-Part 58: Insecticides against leaf-miner on citrus [S]. Beijing: China Standard Press, 2004.

[28] P. Zhang, Q. Lyu, S.L. He, et al., Effects of citrus treeshape and spraying height of small unmanned aerial vehicle on droplet distribution, International Journal of Agricultural and Biological Engineering, 9(4), 2016, 45-52.

[29] H. Zhang, Researches on relationship between the photosynthesis, canopy, and fruit quality of different shapes in citrus, Wuhan: Huazhong Agricultural University, 2012.

[30] L. León, R. De La Rosa, L. Rallo, N. Guerrero, and D. Barranco, Influence of spacing on the initial production of hedgerow-shaped 'Arbequina'olive orchards, Spanish Journal of Agricultural Research, 5(4), 2013, 554-558.

[31] E.R. Trentacoste, D.J. Connor, and M. Gómez-del-Campo, Effect of olive hedgerow-shaped orientation on vegetative growth, fruit characteristics and productivity, Scientia Horticulturae, 192, 2015, 60-69.

[32] S.U. Cherbiy-Hoffmann, P.S. Searles, A.J. Hall, and M.C. Rousseaux, Influence of light environment on yield determinants and components in large olive hedgerow-shaped following mechanical pruning in the subtropics of the Southern Hemisphere, Scientia Horticulturae, 137, 2012, 36-42.

[33] Y. Ru, H.P. Zhou, and C.R. Shu, Deposition evaluation of aerial electrostatic spraying system assembled in fixed-wing, Applied Engineering in Agriculture, 30(5), 2014, 751-757. 
[34] C.R. Shu, H.Y. Pan, H.P. Zhou, et al., Deposition effects of electrostatic and non-electrostatic aerial spray, Scientia Silvae Sinicae, 48(4), 2012, 75-80.

[35] L. Xu, H. Zhu, H.E. Ozkan, W.E. Bagley, and C.R. Krause, Droplet evaporation and spread on waxy and hairy leaves associated with type and concentration of adjuvants, Pest Management Science, 67(7), 2011, 842-851.

[36] H.Z. Yuan, Z.Q. Wang, R.H. Sun, S.F. Li, Z. Dong, and L.P. Sun, Influences of nozzle type and spray adjuvant on the distribution of spray droplets with stretcher mounted sprayer in peach orchards, Plant Protection, 36(1), 2010, 106-109.

[37] D. Nuyttens, K. Baetens, M. De Schampheleire, and B. Sonck, Effect of nozzle type, size and pressure on spray droplet characteristics, Biosystems Engineering, 97(3), 2007, 333-345.

[38] R. Xu, L.X. Li, L.Q. Zhang, B.W. Zhu, X. Liu, and X.B. Bu, Influence of pressure and surface roughness on the heat transfer efficiency during water spray quenching of 6082 aluminum alloy, Journal of Materials Processing Technology, 214(12), 2014, 2877-2883.

\section{Biographies}

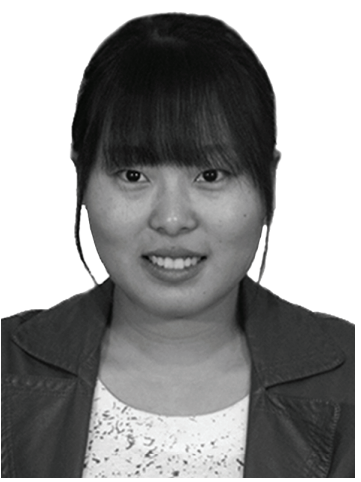

Zhang Pan is a master student of Citrus Research Institute (CRI), Southwest University (SWU). Her research area is mainly about citrus disease and insect control under precision agricultural information technology. She has published two academic papers under Professor Deng Lie's guidance, one of these papers was indexed by SCI. She was also a leader of the project of Fundamental Research Funds for the Central Universities, China.

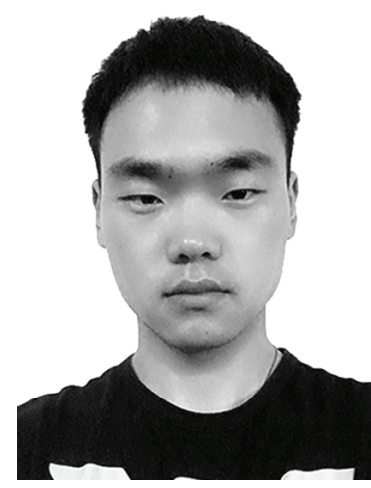

Wang Kejian is also a master student of CRI, SWU. His main research fields are remote sensing technology and its application in citrus orchard. His academic paper was also indexed by SCI. He is the second author because he makes big contribution for this experiment.

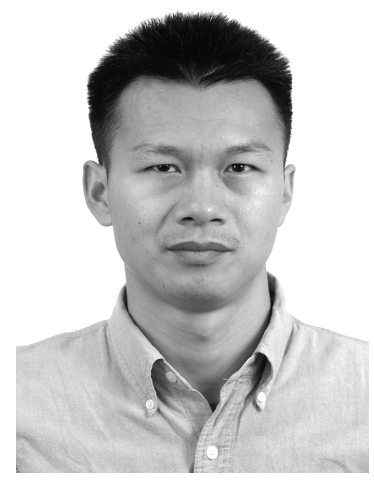

Lyu Qiang received his Ph.D. degree of food science at Jiangsu University (China). His education has a background in computer science and spectrum technique. At present, he is an associate professor of CRI, SWU. He mainly focuses on the area of spectrum technique and remote sensing technology in citrus orchard.

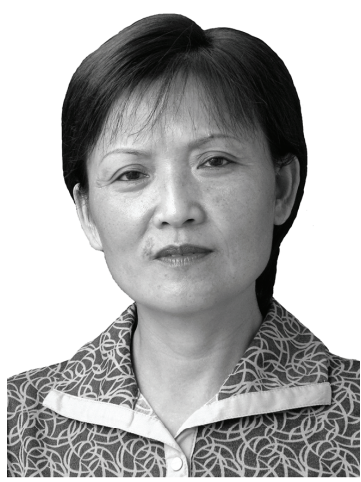

He Shaolan is an associate professor of citrus cultivation physiology for 30 years at SWU, China. She is also interested in agricultural information technology application in citrus orchard. She has served on the editor committee of China Fruit Industry Information.

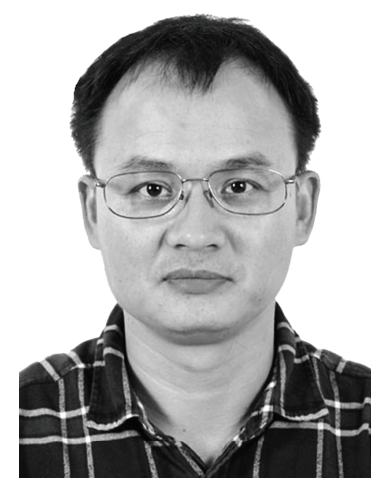

$Y i$ Shilai devote most of his time to soil nutrition and agricultural information technology application in citrus orchard for more than 10 years. He is an associate professor of SWU, China.
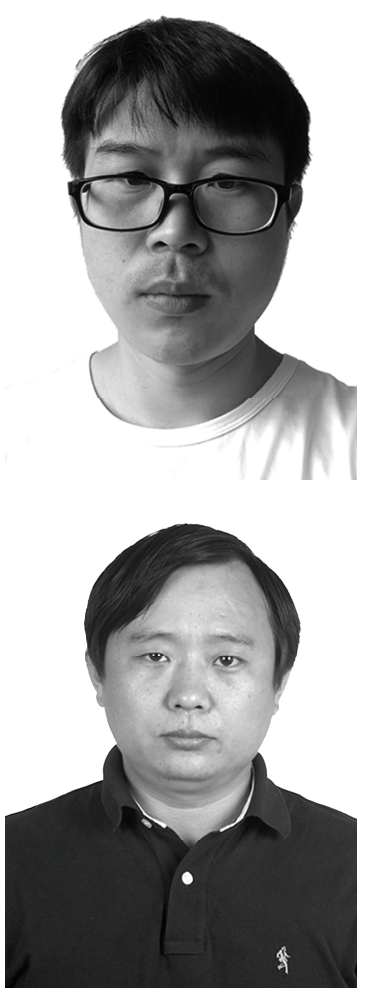

Xie Rangjin mainly focuses on citrus molecule physiology and agricultural information technology. He is an associate professor of SWU, China. He has published many academic papers which are also indexed by SCI.

Zheng Yongqiang is an associate professor of SWU, China. His main research fields are citrus cultivation physiology and citrus information technology.

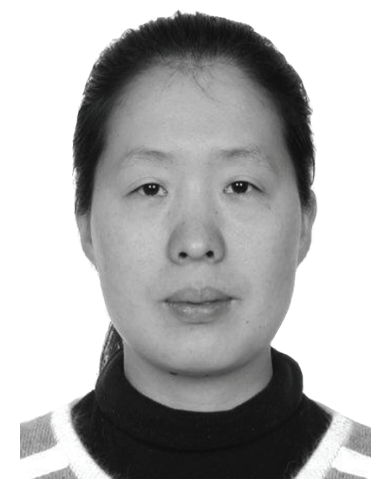

Ma Yanyan received her Ph.D. degree of botany at Southwest University (China). Her research areas are mainly about citrus molecule physiology and citrus information technology. 


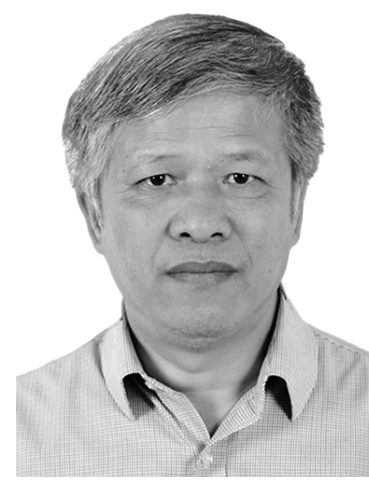

Deng Lie is the corresponding author of our paper. He is a professor of SWU. He has published extensively in the areas of citrus information technology and citrus cultivation physiology. He is also an editor of China Fruit Industry Information and South China Fruits. He was the leader of many national projects and many of his academic research results have successfully applied in citrus orchard, such as the mechanization design methods of citrus hilly orchard, variable fertilization technology, UAV's application in citrus orchard. 